Jeff Bezemer* and Gunther Kress

\title{
Continuity and change: semiotic relations across multimodal texts in surgical education
}

DOI 10.1515/text-2017-0014

\begin{abstract}
In this paper we develop a social semiotic account of continuity and change across texts. Our aims are to make a theoretical contribution to scholarly work on inter-textual relations by adopting a multimodal perspective; and to develop a framework for understanding how texts mediate knowing, learning and agency in education and beyond. We achieve this through a case study of surgical education. We present and analyze, first, a collection of pedagogic texts designed for surgeons learning to perform a common surgical procedure. Second, we look at a series of texts that culminated in a pedagogic text on surgery for the general public. We conclude that a multimodal, social semiotic framework provides essential means for the recognition, documentation and understanding of continuities and changes in text production and engagement.
\end{abstract}

Keywords: social semiotics, multimodality, intertextuality, semiosis, surgical education, retextualization

\section{Introduction}

In this paper we develop an account of continuity and change across multimodal texts. In our social semiotic frame, continuity and change are intrinsic features of unlimited semiosis (Eco 1976), the constant process of the making and re-making of signs. We take it that semiosis is punctuated by moments of fixing and framings (Kress 2000) in textual instantiations, when otherwise invisible semiosis is made material in some multimodal realization: visible, tangible, audible. These fixings and framings provide a momentary view on a sign-maker's semiotic-social position. We want to show that this relies on the

\footnotetext{
*Corresponding author: Jeff Bezemer, UCL Knowledge Lab, 23-29 Emerald Street, London WC1N 3QS, UK, E-mail: j.bezemer@ucl.ac.uk

Gunther Kress, UCL Institute of Education, University College London, 23-29 Emerald Street, London WC1N 3QS, UK, E-mail: g.kress@ucl.ac.uk
} 
recognition of agency: a sign-maker has semiotic choices, and uses these to make different aspects of a phenomenon explicit, or to bring different kinds of phenomena into "visibility," into focus or "noticeability," in ways deemed apt for the audiences of the occasion of production.

In the past decade or so, relations between texts produced in different social sites or contexts have been extensively explored and theorized in linguistic anthropology and linguistic ethnography (Silverstein and Urban 1996; Blommaert 2001; Maybin this issue). While significant in highlighting the social effects of text making across time and space, this work has focused on speech and writing, leaving the role of other modes of representation relatively under-theorized and unaccounted for. Meanwhile, conceptual and empirical work on multimodality in social semiotics and other disciplines has focused on intra-textual relations, notably the relation between image and writing (Barthes 1973; Martinec and Salway 2005; Bateman 2014), leaving the relations between texts relatively under-researched (with some exceptions, see e.g. Kress and Van Leeuwen 2001; Iedema 2003; Prior and Hengst 2010; Bezemer and Mavers 2011).

We will explore semiotic continuity and change across two sets of texts. First, we look at a set of paradigmatically related texts: texts that form a collection of texts that address, broadly speaking, the same audience and make selections from the same body of knowledge, while at the same time showing significant differences in their multimodal design. Second, we look at syntagmatically related texts: texts that form a series, that is, texts in sequence, with one text following on from or operating as a response to a previous text, and each text involving a different set of modes and audiences. This series of texts give us insight into the collective process of designing and producing a pedagogic text.

The framework we develop is grounded in a case study of surgical education. We will show that (surgical) education is one of the domains where the framework can have real effects by rendering visible semiotic work - by educators as much as by trainees - that is often taken-for-granted, unnoticed or unaccounted for, providing opportunities to give due recognition and "credit" to that work. We wish to emphasize that the implications of the framework go beyond surgical education, indeed beyond education, in showing how modes are used to shape texts and textual relations, and in so doing knowing, agency and learning.

The paper is structured as follows. In the first couple of sections of the paper we outline our theoretical framework. Then, following a brief discussion of the origins of our data we present examples of paradigmatically and syntagmatically related texts and explore potentials for and signs of engagement with text. 


\section{Social sites}

We begin our account with a discussion of the social sites where surgical discourse is made and remade. By surgical discourse we mean a body of knowledge and understandings shared by a community of surgeons. We use site to refer to an imagined, institutional site where these discourses are produced and reproduced, as in "the school," "the museum," "the hospital."

Following Bernstein (1996), we use the concept of recontextualization in order to describe how discourses which originate in one social site - he uses the example of Carpentry - are reshaped so as to fit with the social givens of the new site, such as the school, in the school-subject "Woodwork." He was interested in the transformation of discourses along the lines of the social organization of the pedagogic site. In surgical education, we can trace similar processes of transformation, for instance when "surgery" becomes "knot tying," "laparoscopic skills," and so forth.

Like so many professions, surgery has traditionally followed an apprenticeship model. In the United Kingdom, medical students usually start observing in the operating theater in their third year, when the hospital becomes their main site of learning. After they have qualified as a doctor, they go through two foundation years during which they complete rotations of the various specialties, including surgery. Those who opt for a surgical career then embark on an eight-year path of specialist training. After four years of training they apply to become a Specialty Trainee in surgery. When they have completed their training and passed the exam for registration as a Fellow of a Royal College of Surgeons, they can apply to become a consultant surgeon.

In this model, professional discourse and pedagogic discourse are not always spatially (or temporally) separated. For instance, in the operating theater, clinical work is interwoven with pedagogic work. Sometimes one is in focus more than the other, for instance when a surgeon takes time to draw a trainee's attention to structures inside the patient's body. On other occasions, no pedagogic work is visible, as when a surgeon and their assistants are quietly working together. Thus the operating theater is both a professional and a pedagogic site. Texts produced there enact both professional and pedagogic discourses.

In recent decades, however, there has been a trend toward spatial and temporal separation of professional and pedagogic discourses. The "skills" involved in surgery have been made explicit to form the basis for a "competence-based curriculum." In practice, this means that postgraduate trainees, while still spending most of their training time in hospital doing clinical work, now often leave the hospital to attend short courses in lecture halls 
and "skills labs." For trainees, the pinnacle of many of these courses is simulation. Designing simulators, i.e. recreating human anatomy using different technologies (tangible, digital, haptic), has become a major part of surgical education (Prentice 2012).

In the following sections we present and analyze texts from both the operating theater and the skills lab, alongside an example of a text from an online textbook. Each of these texts is designed by surgical educators to create a route to learning for surgeons. We make a distinction between two routes to learning (Bezemer and Kress 2015): through the interpreter's own initiating action: "Route A"; or through the initiating - and shaping - action of some other: "Route B." Whether self-initiated or prompted by an "other," it is the case that all of the world is socially shaped, and saturated with the results of past social semiotic work: all of the present world inhabited by a community, teaches; though its members learn (in interpretation) for the most part (Route B) according to an individual's motivating "interest." That leads to both an ongoing commonality in the development of cultural resources and to essential differences. In a frame in which much is common, there is manageable, productive difference.

In relation to Route $\mathrm{B}$, the community - where, and if, it functions reasonably - has made agreements about those aspects of the social cultural world which are of significance in terms of values, ethics, knowledge, processes, practices. These are of enough significance to become codified in some way and become the object of a requirement for all members of the community to be aware of them, to "know" them, to adhere to them. They become subject to institutionalized processes of being shaped in ways that make them accessible, for all to know - as, for instance, the curricula familiar from institutional sites of teaching and learning. These institutional formalizations and classifications of cultural-semiotic entities are drawn into processes of "verification," through the use of metrics designed to permit assessment of degrees of conformity, of adherence, of understanding. In short, the curricula become the "ground" for a system of assessment, judgment, (e)valuation.

\section{Texts}

We are interested in the texts through which the surgical community creates routes to learning. That is, texts that are pedagogically framed: they materialize a relation of "teacher" on the one side and "learner" ("student," "trainee") on the other. This relation is a specific instance - a pedagogic one - of 
the vastly encompassing general social relation of rhetor and audience. In all instances, the rhetor's orientation is toward shaping the engagement of her or his audience in specific ways, for specific purposes. We might say that that is always the aim of the rhetor. At the same time, now, the (perhaps) still dominant perspective of a directionality from expert/authority to non-expert co-exists with an increasing assumption of the "agentiveness" of those who might previously have been seen as non-experts and (as in need of being treated) as learners therefore.

In social semiotic theory (Hodge and Kress 1988; Kress 2010), a text is a complex of signs which is designed to be internally cohesive and coherent, and which is coherent with relevant other semiotic entities in the context of use; and which its maker treats as complete, in terms of its social use. Signs are units in which meaning and form are brought together in a relation motivated by the interest of the sign-maker. The process of sign-making is always subject to the availability of semiotic resources and to the aptness of the resources to the meanings which the sign-maker wishes to realize. In principle, there are always limitations of semiotic (/modal) resources, even if the limitations always emerge differently. Nevertheless, we treat the design of a text as the sign-maker's apt representation of her or his interest.

The affordances of modes enable sign-makers to do semiotic work in relation to their interests, shaping their rhetorical intentions and adapting to their sense of the needs of the audience. That is, sign-making rests on an assessment of the "aptness of fit" between the affordances of the available modes on the one hand, and the complex and often contradictory demands of their own interest, of the needs of the matter to be communicated and the assumed characteristics of a diverse audience on the other. Given the complex relation of variable social environments, of the rhetor's (and the designer's) interest, of the diversity of audiences, and of modal affordances, design moves into the center of attention in the making of multimodal text.

We define design as the practice where these different factors are brought into coherence with each other: rhetorical purposes and the designer's interests; the semiotic resources; and the assumed characteristics of the audience. From the designer's perspective, design is an intermediary and mediating process that - gives shape to the rhetor's and designer's interest, purposes and intentions;

- is shaped by the semiotic resources available for realizing/materializing these purposes in the form of shaped complex signs;

- addresses the assumed characteristics of a particular audience.

Text is the material form in which these processes of design are given realization. 
Our definition of texts allows us to consider texts of quite different material realizations: some are more permanent, durable, such as a manikin, i.e. a plastic model of a body part (outside surgical education we might consider, e.g. toys; see Machin and Van Leeuwen 2009); others are more "ephemeral," such as texts involving speech, gesture, gaze. These texts can be rematerialized: the model can be photographed, the text made with speech and gesture can be audio- and video-recorded and subsequently transcribed. These re-materializations are at the same time representations (Bezemer and Mavers 2011): The moving image is used to represent gesture, still image is used to represent molding, writing is used to represent speech. These "retextualizations" produce different kinds of semiotic change. We will get back to this concept in the penultimate section.

\section{Data}

The empirical materials we present in this paper were collected between 2009 and 2014 in the context of a series of ethnographic research projects documenting surgical teaching and learning in a major teaching hospital in London. For a more detailed methodological account, see Bezemer (2015). The aim of these projects was to explore surgical training across different sites and at all levels.

The bulk of our materials was collected in operating theaters. The first author of this paper, Jeff, observed 40 general surgical operations. That is the equivalent of more than 80 hours of operating time. The operations ranged from minor operations, described by surgeons as "simple" and "straightforward," such as removal of fatty lumps, skin tag, etc., lasting about 20 minutes, to major operations involving the removal and reconstruction of (parts of) the colon, the stomach, and the esophagus, lasting up to six hours. The overall time we spent observing in theaters exceeded that, covering not only the actual operations but also the preparations and cleaning up in the operating theater and its adjacent rooms: the prep room, where nurses sort the instruments, and the anesthetic room, where the anesthetist puts the patient to sleep. Jeff spent many hours waiting for the next case to start; often, then, opportunities arose to talk to staff and students. He made pictures of the spatial positioning of staff during operations and made photocopies of documents circulating in theaters, such as drawings and sketches made by surgeons, operating lists, log books and operative reports.

During field work Jeff was employed by the Department of Surgery attached to the hospital where the research was carried out, providing a unique opportunity to interact with surgeons and surgical trainees, not only before, during 
and immediately after operations, but also in research seminars, in lectures, in official e-mail circulations, and in informal gatherings, such as Christmas parties. Throughout most of the field work and much of the analysis of the materials he worked closely together with Alexandra Cope, a (then) Specialty Trainee in surgery.

Together Jeff and Alex audio- and video-recorded 15 operations, generating 25 hours of audiovisual material. They used a wireless microphone worn by one of the surgeons, and in-built video cameras, allowing "capturing” that to which surgeons typically orient themselves, that is, their hands, their instruments, and the parts of the patient's body that they operate on. They also recorded the view of the laparoscope, that is, the camera that is used in keyhole surgery to get a view inside of body cavities. Before undertaking the research, they had applied for and obtained approval from the Research Ethics Committee of the National Health Service in England. All staff in theater and all patients who took part in the study gave us informed consent; none of the patients asked raised objections.

In addition, Jeff observed surgical educational activity outside the operating theater on numerous occasions, in particular during the time that he was based in a building which housed the under- and postgraduate skills labs of the surgical department. In addition to these materials, we use one example which draws on our own experiences as "curators" of a public event at a museum, where we re-made one of the texts from inside the operating theater for a general audience.

\section{Paradigmatically related texts}

The texts we will present and discuss now all deal with the same surgical procedure: the laparoscopic cholecystectomy. That is, a gall bladder removal through a minimally invasive procedure (so-called keyhole surgery). In the United Kingdom, all surgical trainees do at least one rotation in general surgery and will experience what it is like to assist in and possibly "do" this procedure.

Each text focuses on those aspects selected from the professional discourse, which are presumed to be necessary to serve the needs of specialty trainees in relation to the laparoscopic cholecystectomy. We might describe the texts as belonging to a paradigm, along with a myriad of other texts that make explicit knowledge about how to remove gall bladders; and the relations between these texts as paradigmatic relations. The texts were designed independent of each 
other, and show significant differences in terms of their multimodal design; and significant continuities in terms of what is signified.

The first text can be found on Medscape, a popular US-based online platform for healthcare professionals (Sherwinter et al. n.d.). The text is part of a "chapter" on Laparoscopic Cholecystectomy Technique, focusing on "the conventional approach" to this procedure.

The second text is represented here as Figure 1. It is a three-dimensional model of an operating theater, complete with equipment and patient. Inside the draped manikin on the table is a porcine model representing a human liver and gall bladder.

The third text is produced by a consultant who is performing a laparoscopic cholecystectomy on a patient. Through dissection he has rendered visible in this

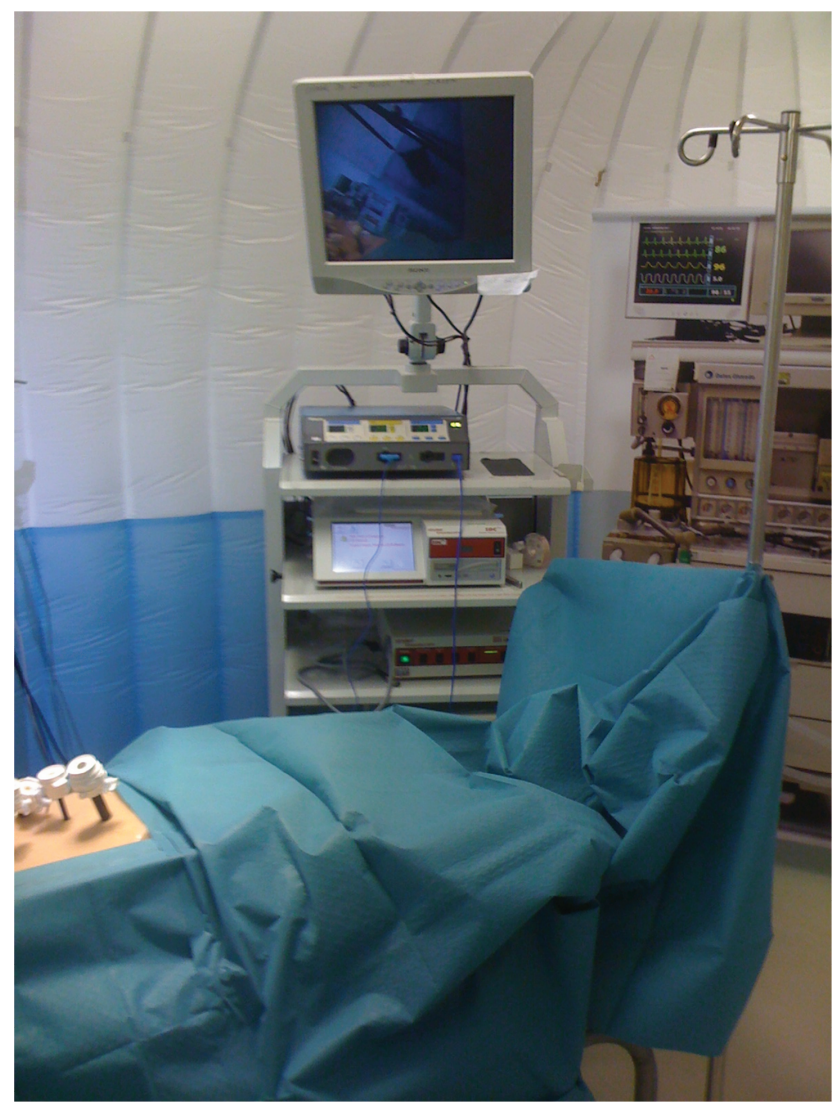

Figure 1: Model of operating theater environment, equipment and patient. 
patient structures known as the cystic duct and the cystic artery. Now he is sweeping his instrument along one of these structures (see Figure 2), while saying, "That's what you call the critical view." He then uses his instrument to point at another structure, as he says, "Here's the common bile duct." Following that he puts clips (staples) in what he just described as the cystic duct and artery, divides these structures, and proceeds to free the gall bladder from the liver bed.

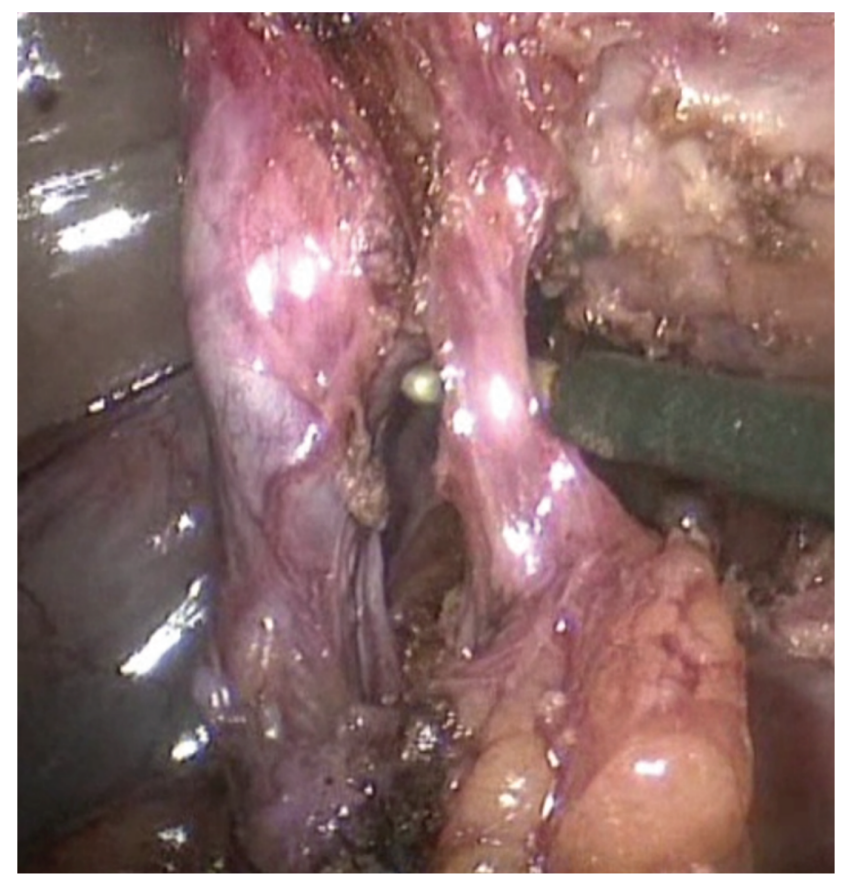

Figure 2: Surgeon examining “Calot's triangle” inside a patient's abdomen.

The semiotic relations between these three texts cannot be understood unless we consider each text in turn as a separate whole. That means giving equal analytical attention to each of the different modes involved. These modes are used to do different kinds of semiotic work; or to do broadly similar semiotic work through the differential use of (elements of) these resources.

In the first text, writing provides a description (a "recipe"; in genre terms a "procedure") of how to remove a gall bladder. For instance, it is explained that 
Once the area of the hilum of the gallbladder has been reached, the importance of exposure and delicate dissection cannot be overemphasized. The cystic duct and artery must be carefully dissected and identified in the triangle of Calot to obtain the critical view. This critical view is achieved when the surgeon can see only two structures (the cystic duct and artery) entering directly into the gall bladder (see the image below); it must be obtained before any structures are clipped or transected. (Sherwinter n.d.)

Image provides details that would be difficult or impossible to describe using words. Thirty images are used in this text: two photographs showing the exterior of the patient's body; and 28 photographs from inside the body made with the laparoscopic camera. The images highlight spatial arrangements, such as the placement of the different entry points for the instruments; and the changing appearance of the structures operated on as the dissection proceeds. They are "snapshots" drawing attention to the shape and color of a focal area at different points in time. The accompanying writing is a commentary on this series of images, used to name structures and states of visibility (the so-called "critical view"). Without the use of either the one or the other, the information provided would be severely limited, relative to the information needed.

The simulator in Figure 1 was designed by a multi-professional team. Using a range of material resources and their potentials for meaning, they jointly created a static, three-dimensional text for surgical trainees. Industrial engineers used inflatable materials and chose colors matching the color of drapes and gowns to represent a clinical space. They used photographic banners to represent various machines, the trolleys packed with sutures and other materials. A model maker used plastic to represent an abdominal cavity and silicone to represent bowels, and a porcine model was used to represent a human gall bladder. Drapes and small objects that were to hand were used to represent the shape of a human body lying under the drape on a table. Authentic equipment was used too, such as the camera and the monitor, used to see inside the patient's body, and the long instruments used in laparoscopic procedures.

In the third text, the surgeon used gesture to point at, and speech to name, anatomical entities. He needed gesture as much as speech to draw the trainee's attention to relevant structures in this patient, and to identify the point at which he believed he had obtained a "critical view." Without either modes of gesture or speech, this brief teaching episode would have been rather different. Naming alone would leave the trainee with the job of establishing exactly what, in this "mess" of "stuff" inside the patient's abdomen, counts as "the critical view" of "cystic duct," "cystic artery" and "common bile duct." Pointing alone would leave the students with the job of establishing what the object is that is marked out by the pointing: that is, what anatomical category it is an instance of. 


\section{Potentialities for learning}

Each mode offers distinct possibilities to shape what is at issue for engagement. The choice of mode has implications for the effectiveness of representation, and so for learning. Affordances of modes are not only shaped and constantly reshaped by a social history and a social present of use, they also shape new signmaking. The units and principles of arrangement that each mode provides offers sign-makers both potentials and limitations and prompts to engage with and to see the world in certain ways, that is to see the world through a lens that organizes that world in specific ways. As each of the three texts presented above is modally different, they create different possibilities for learning.

For instance, in the online textbook photographs are used of anatomical structures at different points during the operation. In operations, both the object that is selected for interpretation and the view of that object is fleeting (Hirschauer 1991): the appearance of the object changes as the surgeons operate on it; and the view of the object is contingent on retraction and camera angle: "stuff" needs to be removed, pushed aside, and so forth for structures to become visible. Trainees may only recognize and identify these structures if the consultant draws attention to them and points at them, as the consultant in our third text did. The photograph freezes such fleeting views at moments selected as criterial by the editor of the text, providing a fixing and framing for trainees. As with any image, the photographs show where anatomical entities are in relation to each other, and give an indication of relative size, shape - whether they are next to each other, or opposite, for instance. Writing and speech do not offer this potential.

We note that the photographs show what named structures look like in one particular patient. It is the task of every trainee to identify the "same" structures in other patients. Line drawings of these structures, which are often included in textbook entries on the laparoscopic cholecystectomy, abstract from the unique features of one patient's anatomy; yet they also omit features such as movement, which are critical in identifying them in real patients (e.g. pulsation of an artery). In both the photographs and the line drawing three-dimensional objects are re-presented as two-dimensional images, resulting in significant gains and losses: lost is depth, for instance, gained is focus (through magnification, for example). In each case the surgical educator exploits the possibilities afforded by the modes used pedagogically (for instance, by freezing a fleeting view).

The designers of the second text have made different selections for representation, and made quite different modal choices. Using molding, color, placement, image and other modes, they have designed a text that looks radically different from the other two texts. 
Compared to the text from the online textbook, it can be said to provide more pictorial detail, and more texture. The latter enables trainees to feel a gall bladder (of a pig) and the effects of invasive actions through their instruments (e.g. actions designed to separate the gall bladder from the liver): touch becomes a central resource. Yet the text does not represent the structures that were shown and discussed in the textbook and by the consultant in the third text. To transpose a porcine liver with gall bladder from a cadaver into a manikin means that the structures connecting the gall bladder to other organs need to be divided by the educator/designer. What remains is a structure that can be used to practice how to dissect the gall bladder from the liver, not how to free and identify the cystic duct and the cystic artery (which surgeons consider to be the most difficult and consequential work of this procedure).

What follows from this is that modes have a large effect in shaping what the sign-maker can do and does; modes set limits to the sign-maker's agency. Modes enforce epistemological commitments (Kress 2010). Given that the potential for making meaning in any mode is always partial, it is not surprising that in each of the three texts presented above signs made in different modes are interwoven, mutually modifying and complementing. By acknowledging the distinct potentials of modes available, we recognize that no two pedagogic texts provide the same potential for learning, even if they were designed to represent the "same" body of knowledge: every text is partial. With the ever-expanding range of texts from which trainees can choose (and create their own "routes" to learning), both digital and tangible, there is an urgent need to develop means for understanding what is unique in each.

\section{Transformative engagement with text}

We use the notion transformative engagement in recognition of the fact that signmakers do not - "simply", to speak - copy, or acquire, somehow straightforwardly internalize or absorb texts made by others. We emphasize the centrality of interpretation. Communication and learning, we hypothesize, rest on interpretation as the outcome of principled, transformative engagement, no matter by whom or how that engagement had been or is shaped.

We make a distinction between learners who were addressed and learners who were not addressed by "shaping agents." They illustrate two routes to learning: (a) through the interpreter's own initiating action, or (b) through the initiating - and shaping - action of some other. Our assumption is that (a) is by 
far the most frequent route, all through life, from the very first to the very last breath of a human being, with one important qualification which we mention in a moment. However, for a group of people to be able to act as a community, for them even to constitute themselves as a community, we assume that route (b) is essential. It requires a community to come to an agreement about the kinds of things that make it a "community," a functioning entity; and which should therefore be presented to any new member as essential knowing in and about the community.

The qualification to (a) is this: from the moment human beings come into the world - and seemingly before - they come into a socially shaped cultural world. Whatever they encounter has been shaped in often very long social histories, whether practices, objects, processes, material or conceptual. While it may well be the interpreter's initiating action which provides the energy to learn, it is, nevertheless, the world engaged with, which is a world that bears, in everything touched and felt, seen or heard, the traces of past social action, of past semiotic work, evident in the forms, the materials, the practices of culture. The world encountered is a world saturated with the traces of past social semiotic work.

It might be that this makes it appear as though as members of a community "interpreters" are quasi "victims," the prisoners of "the social." However, in the (self-initiated) process of their engagement with the world, it is the interpreters' interest that leads them to frame some part of the world as being significant, now, and to engage with particular aspects of the social-cultural world they have framed. That "interested engagement" shows that interpreters select what they wish to engage with. For any one individual, their continuous self-selected choices, the difference in the selection of phenomena, objects, practices from the choices of anyone else, means that no two members of the same culture will ever have made the same choices, or have, at a level that matters, the same set of resources, the same set of values, the same experiences, nor the same interest. For members of a community there is both a commonality of resources and a difference in agency, shaped by their interest. Without that difference, there would be no motor-force for engagement, nor for semiotic continuity and change.

Any and every sign and text tells us something about how a sign-maker knows and sees the world at the time of the production of the sign. It makes evident what the sign-maker (as learner, or otherwise) had attended to, had noticed, and what the effects of such "noticings" are on the sign-maker's/ learner's resources. Take the following example. A surgical trainee is assisting a consultant who is "doing" a laparoscopic cholecystectomy. At one point in the operation the trainee says, "Can I have the endoclips ready please." 
The trainee is addressing the scrub nurse, asking her to unpack a stapling instrument and have it ready to hand. At the same time, the request makes explicit the trainee's interpretation of the state of the operation: he anticipates that the consultant will soon be ready to put staples on the cystic duct and the cystic artery, so that the structures can be divided. It also means that the trainee believes that these structures have been sufficiently freed and cleared by the surgeon to be able to correctly identify them. As texts such as the ones we discussed earlier (which this trainee will undoubtedly have engaged with) emphasize, they must not be mistaken for the structures from which they branch off, or serious complications are likely to arise. Making the request for the endoclips also indicates that the trainee takes it that he is in a position to make that request, and that the consultant agrees with his judgment of the situation.

To give one other example: The drawing in Figure 3 was produced by a surgical trainee as he was addressing another surgical trainee just before the start of an operation. The former had some experience assisting in the scheduled procedure (an esophagectomy), the latter did not. Drawing, here, was one mode in an ensemble of modes used to produce an account of the procedure for the surgical trainee with little experience of assisting in this procedure. It shows how the more experienced trainee knows and sees the world at that point in time. The drawing shows parts of the anatomy. For instance, in the top right corner, we can detect the windpipe and the two primary bronchi leading to the lungs, and the lower part of the esophagus leading to the stomach.

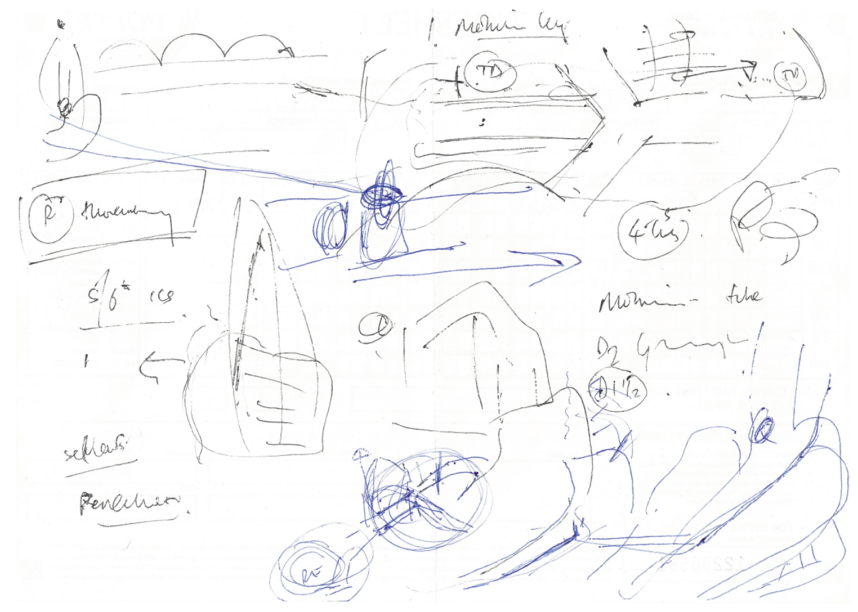

Figure 3: Surgical trainee’s drawing. 
In the top left and bottom right corner, we can detect representations of the stomach and the part where the esophagus enters the stomach, with the location of the tumor ringed.

Continuities and changes can be observed in texts produced by surgical trainees at different points in their training. For instance, Pettinari (1988) looked at the operative reports written by surgical trainees in the United States. An operative report is the "official" documentation of an operation that is added to a patient's files. She found significant differences in the reports written following cholecystectomies. For instance, junior trainees did not describe the common bile duct (the structure that must not be mistaken for the cystic duct), while most senior trainees did. (We note in passing that surgeons occasionally include drawings in operative reports and indeed other types of texts.)

Of course, texts made by learners only give us "glimpses": signs of learning are always partial, as all signs are. The site and occasion of production imposes constraints in terms of what modes can be used to make text. Out of all that which the trainee has learned, through interpretation, or signs made "inwardly" and silently, only selections of these are turned into signs made outwardly, and those outward signs are always made for others, shaped by a rhetorical interest. Indeed, as with sign-making more generally, when looking at texts as signs of learning, we need to attend to the social-rhetorical framing (which is clearly different in the three examples just discussed).

The issue of continuity and change across texts raises another question about engagement, namely how sign-makers - say, in our case, trainees - select and order the texts they want to engage with. Agency here lies firmly with the trainees. Trainees (and educators) have preferences for some texts over others, and for some ordering over another. For instance, one "ideal" pathway might take a trainee from the online textbook to the simulator to the operating theater. This pathway would align with the (still popular) rationale that "theory" comes before "practice" and that "practice on simulators" comes before "operating on real patients." Some surgical educators argue that trainees should practice in a sequence of simulators, reflecting increasing levels of "difficulty," alongside increasing levels of participation in the operating theater.

Yet selection and ordering of texts by trainees is constrained: not all texts are equally available, accessible and affordable. Indeed, the most popular texts - e.g. a "high fidelity" simulator, a consultant-led text in the operating theater - are scarce, and there is significant competition among trainees to engage with them. In the United Kingdom, surgery is notoriously unplanned (even "elective" surgery is), and therefore pedagogic texts emerging there are difficult to "place" in a pathway. Trainees often do not know whether and how 
they will be involved in operations, let alone what operation, until the start of the operation. Preparation may then mean checking texts such as the one in Figure 1 on their mobile phone.

In other words, while some occasions for engagement with pedagogic text can be selected well in advance (e.g. those parts of a course), the usually most valued occasions - those in the operating theater - come unplanned; and they may not result in the most "apt" text for the trainee, given their experience and interests. Thus in practice the "training pathways" that trainees follow do not reflect a rationalized, linear ordering of texts; the texts they engage with do not constitute a coherent whole (they are not chapters in a book); they are, at best, a "collection" of loosely sorted texts.

\section{Syntagmatically related texts}

We now turn to what we describe as retextualization. By that we mean the process of re-materializing a specific text made earlier. The "source" text may be rematerialized in the same or a different social site: not every instance of retextualization is also an instance of recontextualization.

We want to show that the processes of design and production involve retextualization: "conversations" lead to "rough sketches," which gradually become more detailed; images are "translated" into miniature models; and finally into a "finished product," which an audience engages with and possibly rematerializes selections of in some form. Thus we can imagine this as a series of inter-related texts that are made with different modes. This notion of retextualization resonates with what has elsewhere been described as "resemiotization" (Iedema 2003), "semiotic remediation” (Prior and Hengst 2010) and “transmodal redesign” (Mavers 2011).

We focus on retextualizations that culminated in a text in the London Science Museum, where an event had been laid on for an audience of adults, titled, "How Surgeons Learn to Operate.” Figure 4 gives a snapshot of the environment. The text was designed jointly by ourselves and clinical colleagues to engage the general public with surgical education.

In the museum, a consultant surgeon and a trainee surgeon, wearing gowns, were standing on a stage, in front of an operating table with a "draped" "patient" on it. A small screen in front of them showed laparoscopic video footage of a real operation. The surgeons enacted their roles: one holding the camera, the other holding a grasping instrument; both surgeons look at the screen in front of them, as they would have done in the operating theater. On either side of the stage large screens were set up on which the same laparoscopic 


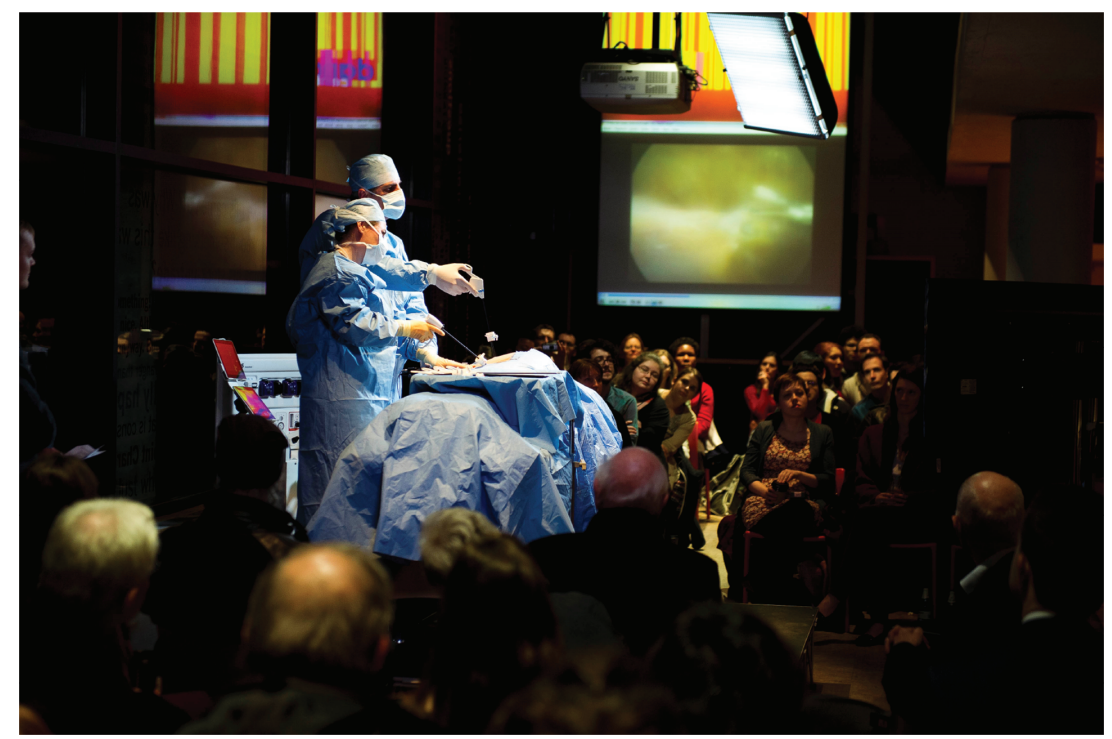

Figure 4: A public engagement event in the London Science Museum (৫ Science Museum Group; reprinted with permission).

recording was projected for the visitors. The surgeons were "acting," applying the instruments and speaking as they might have done in the operating theater, in response to the laparoscopic video that was playing.

The text they made was, to some degree, scripted by us. We had designed a text with a set of 3D objects and a video clip with which the surgeons engaged and to which they added text. We had also written up the lines we wanted them to read, and discussed these with them at a "briefing" just before the simulation. The lines were based on a transcript we had made of the speech recorded on the video clip from the real operating theater. The speaker in the video clip was the same surgeon as the one acting out the consultant in the museum. The role of the trainee was acted out by a different trainee (who had previously been in that role, in that procedure).

The simulation was followed by a discussion with the audience. Members of the audience asked questions, making explicit what they noticed, attended to, engaged with and interpreted. At least one of the visitors made a blog post about the event. ${ }^{1}$

$1 \mathrm{http}$ ///londonaficionado.blogspot.co.uk; see post dated Wednesday, 6 March 2013 (last accessed 27 April 2017). 
Some of what we, and the other sign-makers involved in this engagement event, did can be described as recontextualization: we re-created a text in a museum that originated in the operating theater. It can also be described as retextualization. For instance, we turned a text originally produced with speech, gesture and other modes in the operating theater into a written text (a transcript). That written text was then read out, first, by one of us in the briefing, and then by the surgeons in the simulation. That text was then re-presented in writing and image in a visitor's blog post.

In other words, texts were re-made, retextualized, using different sets of modes. Given the distinct affordances of different modes, there can never be (an assumption of) a "perfect" translation from one mode to another: image does not have "word," just as writing does not have "depiction"; nor does it have the four dimensions that action has. Forms of arrangement ("syntax") differ in modes which are temporally or spatially instantiated (or both, as in gesture). Hence we make a distinction between changes which are "inter-modal" and those which are "intra-modal." Inter-modal changes we call transduction (cf. Jakobson 1959 notion of "transmutation"). They name and describe changes in the move from one mode to another. Intra-modal changes name and describe changes in the arrangement of the elements (of some entity) within one mode. We use the term transformation to describe these kinds of changes. In our example, the transcription of recorded speech is an instance of transduction; and the surgeon "repeating" the lines as previously demonstrated by one of us in the briefing would be an instance of transformation.

Theoretically, in other words, intra-modal changes - transformations - are operations on structures within the one mode, in which the entities remain the same while their arrangement(s) change. In a transformation, say within the mode of writing, words remain, syntactic/grammatical categories remain those of the mode, as do textual arrangements. What changes is their arrangement. In inter-modal changes - in transductions - the change from one mode to another brings with it a change of entities. There are no words in image, there are depictions; semiotic/semantic relations which in speech or writing are expressed in clauses and as verbs are realized through "vectors" or lines. Other semiotic relations between lexical-syntactic elements in speech or writing - prepositions for instance (on, over, by) - are realized by spatial means in images; and so on.

Our point is that modal choices involved in transformation and transduction have epistemological and social effects. They shape what the new text looks like, and therefore what is made available to those who choose to engage with the text and how (in our case, museum visitors). At the same time, they change the resources of the sign-makers who retextualize: by re-making signs in the same or in other modes new understandings are achieved. For instance, the model maker 
used different kinds of images from anatomy atlases representing human organs to create a three-dimensional model of these organs. This process of transduction forced him to make explicit in his model features of the organs that are not specified in image, such as the "texture" of different kinds of human tissue. To "compensate" for this "gap," he frequently talked to surgeons, who described what, say, small bowel feels like: how "elastic" it is, etc. In other words, he used a number of modally different source texts. Each text provided different possibilities for transduction and, in the process, learning.

There is another, more general point to this example. We suggested that the texts we presented constitute a series, that each preceding text was central to the production of the subsequent text. While we do recognize the semiotic continuities across the "series," we also have reservations. First, the texts we presented represent a small selection of momentary framings and fixings. In other words, our account is bound to be incomplete: there are "missing links": texts that we did not document, yet are part of the series. Second, as well as the semiotic relations between two texts produced one after another, we could, and should, consider semiotic relations that "jump over" some inbetween texts: for instance, a spoken comment we had transcribed that was not reproduced in the simulation, but in the discussion with the audience afterwards. Third, texts are never based on one (textual) "source." In our example, the surgeons in the simulation created a new text, drawing on multiple texts at the same time, including the "scripts" we had provided explicating instructions; and non-textual resources, including the professional dispositions they embodied.

\section{Conclusion}

We have highlighted that in a social semiotic account, texts are always seen in relation to prior and future meaning making: each sign draws on historically shaped meaning potential of modes, and with each new sign made, that meaning potential is being expanded. This is a fundamental principle of ongoing semiosis, the constant process of the making and re-making of signs. We emphasized throughout that texts are complex signs, bringing together signs made in the same and in different modes. Each mode provides distinct representational and epistemological possibilities; hence modal choice is central to text design.

We began by considering continuities and changes as discourse from one social site, such as the workplace, is remade in a pedagogic site. We then traced 
continuities and changes in multimodal texts produced in different social sites. We made these visible in paradigmatic relations between relatively independent pedagogic texts; and in syntagmatic relations between relatively interdependent texts. We also looked at continuities and changes as texts are selected, ordered and interpreted by trainees, and described this in terms of transformative engagement.

The framework we develop aims to have real effects on what and whose semiotic work is to be recognized, particularly work which at the moment is often disregarded, may be "invisible" and go unnoticed, or is simply taken for granted, such as the work of assessing what modes to choose for making and remaking a text, given the interests of the sign-makers involved; the work of selecting and ordering texts for engagement; and the semiotic changes produced in doing so. What we are proposing is a framework for making different means for making text recognizable, and giving recognition to different kinds of semiotic change, agency, identity, knowing, learning, everywhere.

This generosity of recognition vastly expands the scope of what is given attention, with significant effects. If semiotic work is not recognized, it can neither be evaluated nor therefore valued. If (institutional) authority is blind to certain means for making meaning, then those who use these means are placed outside the domain of recognition. If institutional authority is regarded as paramount, then much principled semiotic work is ruled out of court.

Socially, these are questions of politics and power; semiotically and pedagogically, they are translated into valuations of different ways of seeing the world. If we wished (educational) institutions to continue to produce conformity and adherence to convention, then two things would need to be maintained. First, the canonically recognized means of making meaning would need to continue to be supported as canonical; other means would continue to be marginalized and kept invisible. Second, theories of learning and communication which privilege authority and its power would have to be defended. This might ensure that notions of "transmission," and "delivery" could prevail; ideologically limited conceptions of innovation and creativity would continue to serve the interests of power.

If, however, it were to be our aim to understand the constantly transformative and innovative character of human meaning making and of learning therefore, then all means used in making meaning will need to be recognized. All signs will need to be taken seriously, regardless of who made the sign, or in what mode; its valuation in the environment in which it was produced will need to be examined and understood. Instead of dismissing signs as "errors" and sign-makers as "incompetent," assessors will be required to investigate and 
establish the semiotic principles applied by sign-makers, to describe their "resourcefulness" (Mavers 2007), and explore and document their "creativity" in conjoining meanings with forms, in instances of the banal and everyday. Creativity, improvisation and innovation will need to be seen as the ordinary, banal, constant processes and phenomena that they are. It will be in the illumination of the principles at work that their enormous richness and potential will be revealed.

Funding: The research was supported by grants from the United Kingdom's Economic and Social Research Council (RES-576-25-0027 and RES-062-23-3219).

\section{References}

Barthes, Roland. 1973. Mythologies. St Albans: Paladin.

Bateman, John. 2014. Text and image. A critical introduction to the visual/verbal divide. London: Routledge.

Bernstein, Basil. 1996. Pedagogy, symbolic control and identity. Theory, research, critique. London: Taylor and Francis.

Bezemer, Jeff. 2015. Partnerships in research: Doing linguistic ethnography with and for practitioners. In Julia Snell, Sarah Shaw \& Fiona Copland (eds.), Linguistic ethnography: Interdisciplinary explorations, 207-224. Basingstoke: Palgrave Macmillan.

Bezemer, Jeff \& Gunther Kress. 2015. Multimodality, learning and communication: A social semiotic frame. London: Routledge.

Bezemer, Jeff \& Diane Mavers. 2011. Multimodal transcription as academic practice: A social semiotic perspective. International Journal of Social Research Methodology 14(3). 191-207.

Blommaert, Jan. 2001. Context is/as critique. Critique of Anthropology 21(1). 13-32.

Eco, Umberto. 1976. A theory of semiotics. London: Macmillan.

Hirschauer, Stefan. 1991. The manufacture of bodies in surgery. Social Studies of Science 21(2). 279-319.

Hodge, Robert \& Gunther Kress. 1988. Social semiotics. Cambridge: Polity.

ledema, Rick. 2003. Multimodality, resemiotization: Extending the analysis of discourse as multi-semiotic practice. Visual Communication 2(1). 29-57.

Jakobson, Roman. 1959. On linguistic aspects of translation. In: Reuben Arthur Brower (ed.), On translation, 232-239. Cambridge, MA: Harvard University Press.

Kress, Gunther. 2000. Text as the punctuation of semiosis: Pulling at some of the threads. In U.H. Meinhof \& J. Smith (eds.), Intertextuality and the media. From genre to everyday life, 132-153. Manchester: Manchester University Press.

Kress, Gunther. 2010. Multimodality: A social semiotic theory of communication. London: Routledge.

Kress, Gunther \& Theo Van Leeuwen. 2001. Multimodal discourse: The modes and media of contemporary communication. London: Arnold.

Machin, David \& Theo Van Leeuwen. 2009. Toys as discourse: Children's war toys and the war on terror. Critical Discourse Studies 6. 51-63. 
Martinec, Radan \& Andrew Salway. 2005. A system for image-text relations in new (and old) media. Visual Communication 4(3). 337-371.

Mavers, Diane. 2007. Semiotic resourcefulness: A young child's email exchange as design. Journal of Early Childhood Literacy 7(2). 155-176.

Mavers, Diane. 2011. Children's drawing and writing: The remarkable in the unremarkable. London: Routledge.

Pettinari, Catherine Johnson. 1988. Task, talk and text in the operating room: A study in medical discourse. Norwood: Ablex.

Prentice, Rachel. 2012. Bodies in formation. An ethnography of anatomy and surgery education. Durham, NC: Duke University Press.

Prior, Paul \& Julie Hengst. 2010. Exploring semiotic remediation as discourse practice. Basingstoke: Palgrave Macmillan.

Sherwinter, Danny A. n.d. Laparoscopic cholecystectmoy technique. http://emedicine.meds cape.com/article/1582292-technique\#c2 (accessed 7 November 2016).

Silverstein, Michael \& Greg Urban (eds.). 1996. Natural histories of discourse. Chicago:

University of Chicago Press.

\section{Bionotes}

\section{Jeff Bezemer}

Jeff Bezemer is Reader in Learning and Communication and Co-Director of the Centre for Multimodal Research at University College London, Institute of Education. His main interest is to develop and apply semiotic approaches to researching clinical practice. Recent book publications include Multimodality, Learning and Communication: A Social Semiotic Frame (with Gunther Kress, 2016) and Introducing Multimodality (with Carey Jewitt and Kay O'Halloran, 2016), both published by Routledge.

\section{Gunther Kress}

Gunther Kress is Professor of Semiotics and Education at University College London, Institute of Education. His interests are in communication and meaning (-making) in contemporary environments. His two broad aims are to continue developing a social semiotic theory of multimodal communication; and, in that, to develop apt means for the "recognition" and "valuation of learning." He is the author of Multimodality: A Social Semiotic Approach to Contemporary Communication (2009), Literacy in the New Media Age (2003) and other books published by Routledge. 